\title{
AVALIAÇÃO JUSTA E DEMOCRÁTICA OU SABER LEGITIMADO COMO PUNIÇÃO? A AVALIAÇÃO PELO OLHAR DA ADF
}

\author{
Dulcinéa Silva Jerônimo* \\ Nádia Dolores Fernandes Biavatit ${ }^{* *}$
}

RESUMO: A partir das teorias que envolvem o processo avaliativo da aprendizagem, torna-se possível conceber a avaliação como ferramenta indispensável na tomada de decisões do professor. $\mathrm{Na}$ verdade, a avaliação, no presente texto, será considerada para além disso, pois destacamos preceitos analisando-os, indicando-a parte constitutiva do discurso escolar e do discurso pedagógico. Nessa direção, pelo aporte da vertente francesa de Análise de Discurso, voltamos nosso olhar para práticas que indicam a ideia de avaliação ideal (e por vezes idealizada) pautada no bom planejamento e condizente com a realidade dos discentes e descrevemos o modo como os discursos funcionam, analisando a tendência de a formação classificatória perpassar o processo avaliativo. Percebemos que o discurso legitimador da avaliação prevalece, superestimando sua face regulatória, na medida em que ela deve fornecer (e muitas vezes não fornece) bons indicadores para os processos de didatização. Ao considerar a escola a partir de uma perspectiva discursiva, destacamos o que acreditamos ser dois fundamentos efetivos diretamente relacionadas à avaliação, a saber: o discurso pedagógico e o discurso escolar - a partir das concepções de Orlandi (1996). Nessa perspectiva, no presente texto, traçamos, pela ótica francesa de Análise de Discurso, uma reflexão acerca das estratégias avaliativas, a fim de buscar compreender melhor o processo de acompanhamento da aprendizagem, sua função e a forma como os discursos perpassam o contexto escolar, especificamente na avaliação escolar de aprendizagem.

PALAVRAS-CHAVE: Avaliação; Análise do discurso; Discurso pedagógico; Discurso escolar.

\section{Introdução}

A avaliação escolar é uma prática rotineira da instituição escolar que, a princípio, visa a detectar o quanto foi apreendido pelo aluno no decorrer de um determinado período. Entretanto, por diversos fatores, os diagnósticos e constatações acabam sendo, muitas vezes, falhos e excludentes, pois avaliar envolve valores que implicam escolher alguns caminhos e negar outros pontos de vista que cercam a dinâmica escolar. O que se percebe é que

\footnotetext{
* Mestranda no Programa de Pós Graduação em Letras - Teoria Literária e Crítica da Cultura, na linha de pesquisa Discurso e Representação Social, da Universidade Federal de São João del-Rei (UFSJ).

${ }^{* *}$ Doutora em Estudos Linguísticos pela Universidade Federal de Minas Gerais (UFMG). Professora adjunta da Universidade Federal de São João Del-Rei (UFSJ), onde atua no Programa de Mestrado em Letras: Teoria Literária e Crítica da Cultura.
} 
o uso dos métodos avaliativos acaba por priorizar a aprovação e a reprovação considerando a tendência da sociedade de marcar a dinâmica competitiva na escola, sem levar em consideração o real objetivo de avaliar: direcionar o processo de ensino, calibrando atividades que possam ajudar e ampliar as aprendizagens a partir dos resultados obtidos.

Tendo em vista que o atual sistema educacional brasileiro prioriza um modelo de avaliação classificatório, focado em números e estatísticas de resultados e comparações entre desempenho dos alunos, o professor acaba seguindo essa tendência sem aproveitar as vantagens e possibilidades de uma avaliação diferenciada. O que se defende no presente texto e tomamos como problematização é a tendência de competitividade social que se reflete na rotina da sala de aula e, ao mesmo tempo, refrata a tendência social de favorecer aqueles que conseguem responder questões conforme solicitado, na sociedade, na escola e em avaliações (BARRETO, 2001), tornando a avaliação uma prática legitimada, rotineira, reguladora e limitadora, por vezes, da dinâmica escolar. Tal modelo parte do pressuposto da homogeneidade, no qual todos os alunos aprendem da mesma forma e possuem as mesmas dificuldades. No entanto, segundo Esteban (2003) a inexistência de um processo escolar capaz de atender às particularidades das classes populares, e que permita que múltiplas vozes possam ser explicitadas e incorporadas, é um dos fatores que contribuem para que um grande potencial humano seja desperdiçado. Assim sendo, a avaliação privilegia aqueles alunos cujas rotinas estão fundamentadas na competitividade do modelo capitalista, na esperteza e no cálculo de habilidades requeridas e daqueles que não conseguem competir ou adaptar-se a essa dinâmica.

Nesse sentido, as postulações de Orlandi (1996) acerca do discurso pedagógico nos parece corroborar o papel que se tem dado à avaliação escolar da aprendizagem, uma vez que o discurso que ainda prevalece no ambiente escolar é o autoritário. A partir deste, o aluno é colocado sobre tutela, tendo em vista que a partir de construções do tipo "é porque é", que constituem o processo de ensino, o conhecimento é inculcado no aluno, desconsiderando o seu conhecimento prévio e, consequentemente, silenciando o aluno.

A instituição escolar em muito reflete a posição de assujeitamento assumida pelos indivíduos, posição descrita na primeira e segunda fase dos estudos pecheutianos. É parte 
do processo de assujeitamento negar as individualidades dos alunos, delimitando o que é o mesmo ritmo de aprendizagem para todos. Ou seja, existem variadas realidades dentro do contexto da sala de aula, o que torna praticamente inaceitável conceber uma mera prova escolar como a milagrosa ferramenta que detectará o conhecimento que cada um dos alunos foi ou não capaz de adquirir. É o que explica Amorim, Magalhães:

A avaliação precisa ser parte de todo o processo de ensino, em vez de simplesmente aparecer no final de uma lição ou capítulo como forma de checar se nossos objetivos foram atingidos. Já que o processo de aprendizagem é contínuo (nós nunca paramos de aprender, não é?), então a avaliação também precisa ser. (AMORIM; MAGALHÃES, 1998, p. 82)

Por essa razão, é importante que o processo avaliativo seja compreendido como uma etapa do processo educativo, ferramenta a ser utilizada continuamente, de maneira que todos os discentes sejam observados a partir das suas individualidades. Quando se avalia todo o contexto e o período da aprendizagem, torna-se possível detectar o ritmo de aprendizagem de cada um dos alunos e, perceber que todos podem alcançar resultados, mas nunca - ou raramente - ao mesmo tempo.

Assim, o presente artigo pretende traçar uma análise acerca das concepções da avaliação da aprendizagem, além de refletir sobre os discursos que perpassam as instituições escolares e como eles refletem nas práticas pedagógicas, identificando especialmente o modo como esse discurso é capaz de interferir no processo avaliativo.

\section{Concepções sobre a avaliação escolar da aprendizagem}

Muito se fala e se pratica no que diz respeito à avaliação da aprendizagem. No entanto, em meio a tantos conceitos, é importante destacar o que é realmente relevante para a melhoria dos métodos avaliativos. Para isso, inicialmente é importante apresentar uma concepção sobre o que representa este processo pelo estudioso da educação Luckesi (2002):

[...] avaliação pode ser caracterizada como uma forma de ajuizamento da qualidade do objeto avaliado, fator que implica uma to- 
mada de posição a respeito do mesmo, para aceitá-lo ou para transformá-lo. A avaliação é um julgamento de valor sobre manifestações relevantes da realidade, tenso em vista a uma tomada de decisão. (LUCKESI, 2002, p. 33)

Desse modo, há uma forma de observar o que foi ensinado, a partir do mecanismo/prática avaliativa, que reflete, em geral, a velocidade, o meio e o modo de ensinar regrados (BIAVATI, 2009), indicando que o processo é legitimado, pois traz a medida do quê e como cada aluno deve aprender e "ser cobrado" pelo apreendido. O processo de avaliação da aprendizagem, conforme reitera Luckesi (1996), segue basicamente a três passos. No primeiro, o professor acompanha o aprendizado do aluno da forma mais individualizada possível, o que talvez vá à contramão do que a escola venha praticando, até com o seu modo de se organizar, atualmente, com sala cheias e tendência de homogeneização dos processos, pois poucas vezes se vê a valorização do ritmo, suas facilidades, preferências e dificuldades (constatação da realidade) com trabalhos e atividades que diferenciem os processos em sala de aula, mesmo porque cada professor tende a ter mais de 40 alunos em sala de aula e, no mínimo, três turmas. Em segundo lugar, Luckesi (1996) descreve a necessidade de o professor comparar a sua constatação com aquilo que julga indispensável no processo de ensino (qualificação). Finalmente, em terceiro lugar, o autor aponta que é parte do processo de avaliar que o professor tome as decisões que possibilitem atingir os objetivos desejados. Partindo dessa concepção, só no terceiro passo ocorrerá a avaliação formal tão priorizada na educação brasileira. Neste momento, o professor já será capaz de realizar uma correção coerente às necessidades do seu aluno. Portanto, o processo de avaliação da aprendizagem inclui também o acompanhamento do ensino e aprendizado.

Deve-se ainda, compreender que a prática avaliativa está diretamente ligada às práticas utilizadas para o ensino. Para além disso, é ela que segue como um modo de ver o processo de didatização que pode representar no mínimo três caminhos: "o que o professor deseja que o aluno saiba"; "o que o professor cobra do aluno, visando-o punir por seu comportamento"; "o que o professor cobra para que o aluno consiga a nota". Assim, estratégias de ensinar e o modo de ver o mundo e o aluno refletirão no processo avaliativo. A partir desta perspectiva, Esteban (2003) desafia o professor a produzir uma avaliação 
dialógica, que esteja ligada à complexidade da vida real, bem como aos múltiplos conhecimentos e individualidades dos alunos.

Embora não seja uma tarefa simples, uma avaliação dialógica possibilita investigação e questionamento constante e se torna um instrumento indispensável ao professor que se compromete pela busca de uma escola democrática.

Dessa forma, pode-se compreender o processo de avaliação da aprendizagem como uma parte do sistema educacional que objetiva detectar não só o que o aluno aprendeu, mas também um método capaz de evidenciar quais os pontos da proposta pedagógica do professor devem ser alterados ou repetidos. A prática educativa, nesse caso, se torna regulada e reguladora da realidade, de maneira que o professor torne essa prática legitimada favorável ao aluno. Assim, Luckesi (1998) propõe que, através dos resultados obtidos na avaliação, o professor busque uma reorientação imediata para casos de qualidade insatisfatórios ou uma progressão do ensino para casos em que a avaliação alcançou os resultados almejados.

Ainda que não seja um processo muito simples avaliar, é importante que a avaliação seja proporcional ao que foi trabalhado no contexto de sala de aula e à realidade dos alunos. “... não é democrático estabelecer objetivos cujo alcance esteja acima das reais possibilidades dos alunos" (LIBÂNEO, 1994, p. 203).

O que se percebe é que, na medida em que se buscam informações sobre o real objetivo e valor da avaliação da aprendizagem, torna-se possível perceber melhor os pontos positivos de uma avaliação bem elaborada e o quanto essa ferramenta se faz necessária no contexto de sala de aula. Assim, o que deve ser buscado, continuamente, é o aperfeiçoamento desse método, de modo que ele não seja apenas um detector do fracasso escolar, mas um direcionador das estratégias do docente. O grande desafio é, portanto, tomar o processo de competitividade que representa a avaliação para torná-la direcionadora, menos punitiva.

Por outro lado, o aluno deve estar ciente da função de cada avaliação. Mesmo que, pela visão discursiva, haja um assujeitamento do aluno ao avaliar, o professor precisa 
tentar reverter o processo avaliativo para que o aluno aprenda, inclusive, na/ com a avaliação. Um processo avaliativo mal estruturado pode simbolizar apenas uma classificação de quem sabe mais ou menos, ressaltando somente a prática da competitividade. De outro modo, ressalta-se o papel político da avaliação, como discurso que coloca os sujeitos interpelados pelos regramentos da escola. Mesmo sendo parte do discurso autoritário da escola, se o viés punitivo sobrepuser o objetivo de aprendizagem, a avaliação deixará de cumprir o seu papel democrático. É o que afirma Esteban:

A avaliação escolar, nesta perspectiva excludente, silencia as pessoas, suas culturas e seus processos de construção de conhecimentos; desvalorizando saberes fortalece a hierarquia que está posta, contribuindo para que diversos saberes sejam apagados, percam sua existência e se confirmem como a ausência de conhecimento. (ESTEBAN, 2003, p. 15)

Por isso, é inegável a importância de salientar que as turmas são heterogêneas, assim como a forma e o tempo de aprendizado. Ainda que a busca por um processo avaliativo que vise a atender as particularidades dos indivíduos e o seu espaço dentro da sociedade não seja uma tarefa fácil, é essencial buscar pelo aperfeiçoamento do que se tem feito dentro do contexto de sala de aula, de modo a garantir a eficácia da avaliação.

Nesse contexto de discussão, a avaliação formativa emerge da perspectiva do feedback ao aluno, permitindo-lhes questionar e refletir acerca do processo. O aluno, portanto, precisa estar consciente da real função da avaliação: fazê-lo refletir sobre o que aprendeu. Nessa ferramenta, a análise dos resultados reavalia erros e acertos, transformando a avaliação em um novo momento aprendizagem.

Uma avaliação formativa ajuda o aluno a compreender e a se desenvolver. Colabora para a regulação de suas aprendizagens, para o desenvolvimento de suas competências e o aprimoramento de suas habilidades em favor de um projeto. Um professor comprometido com a aprendizagem de seus alunos utiliza os erros, inevitáveis, sobretudo no começo, como uma oportunidade de observação e intervenção. (MACEDO, 2007, p. 118) 
Como postulado, na avaliação formativa, há espaço para troca, possibilidade de interação entre professor aluno. Nesse viés, Orlandi (1998) discorre acerca da importância do deslocamento de sentidos no jogo na e sobre as regras da língua.

Pensando então as diferentes posições no discurso pedagógico, a posição-aluno e a posição-professor, podemos dizer que elas se constituem de gestos de interpretação diferentes. Isto quer dizer que na relação professor/aluno deve haver um espaço de jogo que possibilite a transferência, trabalho de memória que permite a repetição histórica, deslocamento de sentidos. (ORLANDI, 1998, p. 16)

Deste modo, tendo em vista que a avaliação formativa prioriza a interação entre aluno e professor para a análise dos resultados, temos, assim, nesse processo, um "espaço de jogo" para os deslocamentos de sentidos e transferências propostas por Orlandi (1998) a partir da perspectiva do discurso. Destacaremos, portanto, que há uma tendência de apagamento da tendência formativa da avaliação, para que a faceta classificatória apareça, com grande força.

\section{Avaliação justa e democrática ou saber legitimado como punição?}

Considerando o ambiente escolar enquanto um espaço em que circulam os mais diversos discursos, tomemos as postulações da Análise do Discurso Francesa (ADF) de modo a compreender o modo como as relações entre sujeitos - através da linguagem interferem no processo de ensino e na avaliação escolar.

Pêcheux (1990) buscou contrapor o conceito de língua enquanto mero instrumento de comunicação a partir da concepção do discurso como um efeito de sentido entre locutores que está, portanto, acima de uma mera transmissão ou troca de informações. Ao tomar a ideia de sentido entre interlocutores, entendemos que há a oportunidade conhecer e desnaturalizar as práticas e as interpretações que estão embutidos tanto na instituição escolar, quanto na historicidade que atravessa essa instituição, seus preceitos e práticas pedagógicas, tornando formas de discurso que circulam na sociedade, na escola e na sala de aula. Nesse viés, o autor considera que a língua está para além da comunicação de modo que o discurso pressupõe o funcionamento da linguagem a partir da relação entre sujeitos 
afetados pela língua e pela história.

Nessa perspectiva, ao considerar que o objeto de estudo da análise do discurso é o próprio discurso, Pêcheux (1990) destaca a importância do conceito de instituição para a construção desse objeto, bem como o tipo de funcionamento que lhe pode designado. Desse modo, tal conceito volta-se para uma abordagem acerca da posição, dos lugares de fala e das condições de produção, ao passo que essas mesmas condições de produção representam, exatamente, o tipo de funcionamento direcionado ao discurso.

A escola se dá como instituição que, como parte da ordem social, estabelece o que deve e como deve ser dito sobre a língua, sobre a rede de comportamentos formais mais aceitos, estabelecidos. Orlandi (1996) conceitua o discurso pedagógico a partir de sua circularidade, tendo vista que se trata de um dizer institucionalizado que possibilita garantir a instituição da qual se origina e para a qual ele tende, ou seja, a própria escola. O discurso escolar segue a tendência dos Aparelhos Ideológicos do Estado (ALTHUSSER, 1985), apropriado para assujeitar os sujeitos aos micropoderes institucionais, ditando como o sujeito deve ser comportar-se diante do saber legitimado e regrado. Por isso, o fato de estar ligado à instituição escolar faz do discurso pedagógico o que ele é, revelando a sua função de preparar o aluno para ser o sujeito "ideal", subalterno à rede de micropoderes na sociedade. É a partir da escola que, segundo Orlandi (1996), aquilo que poderia ser considerado ocasional, considerando-se a perspectiva do aluno, é substituído por um "estatuto de necessidade" a partir da própria avaliação que a escola produz, a qual acaba por instituir um "saber legítimo" que desconsidera outros saberes, outras formas de dizer.

Entendemos que a avaliação é prática discursiva pedagógica e escolar, constitutiva dessa dinâmica escolar. Isso significa que a ideia de avaliar já carrega marcas do discurso autoritário descrito por Orlandi, ao cobrar regramentos e classificar o saber instituído. Assim, o saber legitimado constitui a avaliação como uma etapa em que se cobra o quê e como o aluno deve apreender o que foi ensinado e voltar para o interlocutor o já-dito no cotidiano das aulas. Para o aluno, a ideia de avaliar nos moldes tradicionais acaba se tornando a oportunidade de somar pontos à medida que ele é capaz de efetuar a reiteração de ações solicitadas e de repetição dos conteúdos. 
Sendo assim, passemos a considerar o processo de avaliação escolar como parte do discurso pedagógico, tendo em vista que esse processo é, por vezes, autoritário e, minimamente, democrático. Analogamente, tomemos a concepção de Orlandi (1996) acerca do discurso pedagógico autoritário que tem prevalecido nas instituições escolares:

Enquanto ele for aluno "alguém” resolve por ele, ele ainda não sabe o que verdadeiramente lhe interessa, etc. Isso é a inculcação. As mediações, nesse jogo ideológico, se transformam em fins em si mesmas e as imagens que o aluno vai fazer de si mesmo, do seu interlocutor e do objeto de conhecimento vão estar dominadas pela imagem que ele deve fazer do lugar do professor. (ORLANDI, 1996, p. 31)

Nesse sentido, buscando a manutenção dessa imagem que o aluno "deve fazer do lugar do professor" temos, muitas vezes, um processo de avaliação cujo objetivo não é apenas avaliar, mas também punir aquele aluno que se comportou mal durante as aulas.

Foucault $(1987 ; 2005)$, ao analisar instituições, destaca a escola como um espaço em que há uma rede de micropoderes em que há o domínio dos sujeitos pelas práticas cotidianas. Avaliar como punição é uma forma de exercício de micropoderes da instituição e do professor. Moretto (2001) trata a punição no processo educativo em duas percepções diferenciadas. Em uma a punição está voltada para a elaboração de uma prova difícil, capaz de punir realmente aqueles que agiram em desacordo ao proposto nas aulas. Já na segunda percepção, o professor não tem a intenção de punir, mas, ao elaborar uma prova maçante e desproporcional ao que foi trabalhado nas aulas, ele acaba sendo injusto e punindo o aluno com uma nota baixa, não por culpa do discente, mas sim em decorrência de uma avaliação mal elaborada. E quando se fala em injustiças no processo avaliativo, percebe-se que qualquer detalhe transforma-se em obstáculo para o sucesso dos alunos. Um exemplo claro é o tempo para a execução das provas.

Além do tempo incompatível, muitas vezes usado como forma de pressão sobre o aluno, outra questão recorrente é a quantidade de conteúdo avaliado. Em muitos casos, uma única prova tem a função de avaliar uma série de conteúdos o que acaba dificultando ainda mais a tarefa dos alunos. Ocorrem ainda, situações em que esses conteúdos não são, 
pelo menos, relacionados durante avaliação. Ou seja, se a avaliação endossa o caráter punitivo do processo, o aluno se vê diante de uma prova que cobra uma grande diversidade de conteúdos de forma desconexa e ainda com pouco tempo para execução.

Como percebido, o medo da avaliação é prática institucional decorrente do pleno exercício disciplinar do processo de adestramento dos corpos (FOUCAULT, 1987) decorrente de uma série de circunstâncias que, comumente, ocorrem na vida escolar dos alunos. Assim, pelo viés discursivo, inda que se reconheça o assujeitamento do aluno aos preceitos dessa prática institucional, o modo de construção e aplicação da avaliação deve minimizar o processo, pois os docentes devem estar preparados para avaliar de forma coerente e justa, sem punir, mesmo que indiretamente. Para isso, uma saída considerável é se questionar enquanto profissional da educação: o que eu posso fazer para minimizar a tendência de a avaliação colocar-se como punitiva? Como posso modificar a elaboração das minhas provas escritas? Será que estou realmente avaliando meus alunos de forma qualitativa e contínua?

Já que entendemos que a avaliação é uma prática legitimadora e legitimada da instituição escolar, consideremos observações que partem para a minimização do exercício de poder. Acreditamos que não se deve abolir a avaliação da dinâmica da sala de aula. No entanto, deve-se atentar para as surpresas que punem os alunos. Por isso, as provas devem ser marcadas com antecedência para que os alunos estejam preparados. As questões do tipo "pegadinha" devem ser repensadas, pois, por mais que sejam vistas como estratégias para aprimorar a perspicácia dos alunos, elas também prejudicam e traumatizam. Além disso, fatores como linguagem e formulação de exercícios comuns à realidade da turma devem ser observados. Pode-se também abrir espaço para as avaliações em dupla e consulta, quando se julgar prudente. Isso porque esses métodos tranquilizam os alunos e geram resultados positivos, pois fazem com que eles próprios repensem sua posição de estar em avaliação com o colega, tornando-os corresponsáveis por refletir e responder ao solicitado.

Para o momento, não nos aprofundaremos no momento da correção, mas sabemos também que há complexidades que cercam o corrigir, pois há formas de se conceber o certo e o errado. 
Nenhum extremo é válido: considerar que sempre devemos dizer a resposta certa para o aluno ou, do outro extremo, considerar que todo e qualquer erro que ele cometa tenha o caráter construtivo e que ele poderá descobrir todas as respostas. (HOFFMANN, 2006, p. 88)

Essas formas privilegiam o raciocínio do aluno, bem como a sua capacidade de relacionar o conteúdo ao seu conhecimento de mundo. Assim, avançar no processo avaliativo, amenizando a forma legitimada dos micropoderes do assujeitamento do aluno ao processo avaliativo implica que o aluno se veja livre para mostrar o que sabe como simples produto de cobrança. Implica que o professor provoque no aluno o posicionar-se criticamente sob as mais diversas formas. Ou seja, a avaliação deixa de ser inflexível e automatizada para se transformar em um espaço de posições a opiniões com conhecimento associado. É de extrema importância que o professor tenha em mente que existem diversas formas de interpretação consequentes da multiplicidade dos pontos de vista de cada aluno.

Nessa perspectiva, destacamos as postulações de Orlandi 2003 acerca do discurso polêmico enquanto alternativa ao discurso autoritário do professor. Nesse discurso os alunos encontram espaço para expressarem sua criticidade, discordando, apontando caminhos e considerando as suas vivências. Assim, "ser crítico, tanto pelo lado do locutor quanto do ouvinte, é questionar as condições de produção desses discursos" (ORLANDI, 2003, p. 86).

E é a partir da diversidade de opiniões, de saberes e de reflexão, tanto para professores quanto para alunos, que o exercício avaliativo torna-se necessário para abrir-se ao modo como o aluno chegou às respostas, tornando um pouco mais complexa a reflexão sobre certo e errado. Muitas vezes, o aluno pode ser punido em uma avaliação por se posicionar de forma diferente à esperada pelo professor. Por isso, é importante observar as inúmeras respostas possíveis para uma única pergunta. Contudo, ainda persiste uma "homogeneidade" direcionada ao conhecimento que é criada pela própria instituição, própria do exercício de poder exercido a partir do discurso autoritário, que resvala nos discursos escolar e pedagógico. 


\section{Considerações finais}

Tendo em vista as reflexões apresentadas neste texto, foi possível corroborar o funcionamento da instituição escolar, descrevendo especialmente o modo de funcionamento dos discursos escolar e pedagógico. Para além do discurso autoritário que perpassa o avaliar, a avaliação precisa ultrapassar os objetivos quantitativos da aprovação e reprovação, uma vez que é também capaz de formar o aluno enquanto cidadão crítico e comprometido com a sua realidade. Uma avaliação bem elaborada, que é fruto de um trabalho de observação e diagnóstico das individualidades do aluno, seja no âmbito escolar ou nos aspectos sociais em que ele está inserido, reflete positivamente no trabalho do professor. Em face disso, a função docente é a de tornar a avaliação não o fim escolar e o produto de ações pedagógicas, mas uma ferramenta capaz de direcionar as suas estratégias de ensino.

Por outro lado, um processo avaliativo mal formulado e que busque apenas punir o aluno indisciplinado ou reafirmar a posição autoritária do professor enquanto único detentor do conhecimento pode deixar marcas profundas e inapagáveis, uma vez que irá simbolizar o fracasso sem considerar o quanto o aluno progrediu mediante as suas dificuldades. Assim, nos dizeres de Orlandi (1996) o discurso autoritário do professor pode ser substituído pelo discurso polêmico, a partir do qual há espaço para o ouvinte enquanto "sujeito", ou seja, é preciso abrir espaço para o aluno e também se colocar na posição do ouvinte.

Sendo assim, é importante que os docentes estejam dispostos a transformar seus métodos a partir do conceito de avaliação contínua e qualitativa. Tendo o professor o objetivo de transformar os resultados obtidos na prova em melhoria das propostas pedagógicas de ensino, as avaliações deixam de ser um momento de medo e apreensão, pois se tornam democráticas, capazes de considerar outras formas de saber e de romper com a homogeneidade de um saber legitimado que por vezes tem sido reafirmado nas instituições escolares.

A partir de tais mudanças, os alunos perceberão que o fato de estarem sendo avaliados não significa um acerto de contas, mas o momento de assimilação do conteúdo aprendido durante as aulas e de percepção do conhecimento prévio que ele possui. Nessa nova concepção, não existem erros e acertos, mas sim continuidade ou modificação das técnicas 
de ensino.

A partir das postulações apresentadas, foi possível, sobretudo, identificar a importância do discurso no processo avaliativo, percebendo que um discurso autoritário, que silencia, não colabora para um processo avaliativo eficaz. Todavia, o deslocamento de sentidos propiciado pela troca entre professor e aluno - conforme proposto pela perspectiva da avaliação formativa e do discurso polêmico de Orlandi (1996) - contribui para que a avaliação seja um instrumento norteador, capaz de motivar mudanças a partir da análise de resultados.

\title{
FAIR AND DEMOCRATIC EVALUATION OR KNOWLEDGE LEGITIMATED AS PUNISHMENT? EVALUATION THROUGH ADF'S POINT OF VIEW
}

\begin{abstract}
Based on the theories which involve the evaluation process of learning, it becomes possible to conceive the evaluation as an indispensable tool in teacher's decision making. In fact, the evaluation, in this text, will be considered beyond that, since we highlight precepts analyzing them, indicating the constitutive part of the school discourse and the pedagogical discourse. In this way, from the contribution of the French Discourse Analysis, we turn our attention to practices that indicate the idea of an ideal evaluation (and sometimes idealized) based on good planning and compatible with the students' reality and we describe how the discourses work, analyzing the tendency of the classificatory formation passing through the evaluation process. We realize that the legitimating discourse of the evaluation prevails, overestimating its regulatory characteristic, insofar as it must provide (and often does not provide) good indicators for didactic processes. Considering the school from a discursive perspective, we highlight what we believe to be two effective principles directly related to evaluation, videlicet: the pedagogical discourse and the school discourse - based on the Orlandi's concepts (1996). In this perspective, in this paper, we outlined from the French Discourse Analysis' perspective a reflection on the evaluation strategies, in order to better understand the process of monitoring learning, its function and the way the discourses permeate the school context, specifically in school learning assessment.
\end{abstract}

KEYWORDS: Evaluation; Discourse Analysis; Pedagogical discourse; School discourse.

\section{REFERÊNCIAS}

ALTHUSSER, Louis. Aparelhos ideológicos de Estado. Rio de janeiro: Graal, v. 2, 1985.

AMORIM, Vanessa; MAGALHÃES, Vivian. Cem aulas sem tédio. Porto Alegre: Padre Reus, 1998.

BARRETTO, Elba Siqueira de Sá. A avaliação na educação básica entre dois modelos. Educação \& Sociedade, ano XXII, no 75, Agosto/2001. 
BIAVATI, Nadia Dolores Fernandes. Entre o fato e a regra: unidade e fragmentação na constituição da identidade e representação de valores e práticas do professor-mosaico. 2009. Tese (Doutorado em Estudos Linguísticos) -Faculdade de Letras, Universidade Federal de Minas Gerais, Belo Horizonte, 2009.

ESTEBAN, M. Teresa. Avaliação: uma prática em busca de novos sentidos. Rio de Janeiro: DP\&A, 2003.

- Microfísica do poder. 21. ed. Rio de Janeiro. Graal, 2005.

. Vigiar e punir: nascimento da prisão. 30. ed., Petrópolis, RJ, Vozes. 1987.

HOFFMANN, Jussara. Avaliação mediadora: Uma prática em construção da pré-escola à universidade: Editora Medição, Porto Alegre, 2006.

LIBÂNEO, José Carlos. Didática. São Paulo: Cortez, 1994.

LUCKESI, Cipriano C., Avaliação da aprendizagem escolar. São Paulo, Ed. Cortez, 1996.

. Carlos. Verificação on avaliação: o que se pratica a escola? São Paulo: FDE, Série Ideias n. 8, 1998.

MACEDO, Lino de. Avaliação na educação. Marcos Muniz Melo (Organizador). 2007.

MORETTO, Vasco Pedro. Prova - um momento privilegiado de estudo: não um acerto de contas. Rio de Janeiro: DP\&A, 2001.

ORLANDI, Eni Puccinelli. A linguagem e seu funcionamento: as formas do discurso. Campinas: Pontes, 4. ed. 1996.

. Paráfrase e polissemia: a fluidez nos limites do simbólico. Rua, v. 4, n. 1, p. 9-20, 1998.

Pontes, 2003.

. A linguagem e seu funcionamento: as formas do discurso. 4. ed. rev. e aum. Campinas:

PÊCHEUX, Michel et al. Análise automática do discurso. Por uma análise automática do discurso: uma introdução à obra de Michel Pêcheux. v. 3, 1990.

Recebido em: 28/04/2020.

Aprovado em: 20/05/2020. 